Al-Rafidain J Med Sci. 2021;1;62-71.

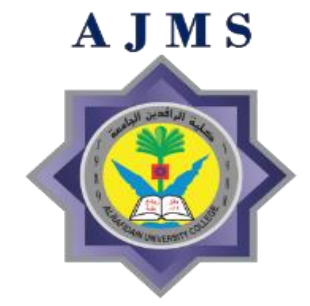

doi: 10.54133/ajms.v1i.37

Review Article

Online ISSN (2789-3219)

\title{
The Role of Autophagy in the Progression and Treatment of Tumors
}

\author{
Ismail I. Al-Janabi \\ Retired Academic, Freelance Consultant Pharmacist and Science Writer, Surrey, England
}

Received: June 2021; Revised: July 2021; Accepted: August 2021

\begin{abstract}
Autophagy is a conserved homeostatic mechanism enabling cells to cope with various stresses. The pathways leading up to the activation of autophagy are interconnected with those of tumorigenesis. However, the relationship between the two events is not a straightforward one and very often context-dependent. Generally, autophagy appears to act against the tumor during the initiation stage and most often drives cancer progression subsequently. Published clinical trials for the treatment of various tumors, where autophagy was pharmacologically inhibited, were obtained and tabulated. Targeting autophagy for the treatment of tumors can be rewarding in the appropriate context, such as cancer type, grade, and microenvironment.
\end{abstract}

Keywords: Autophagy, Cancer, Tumorigenesis, Antitumor therapy, Autophagy modulators

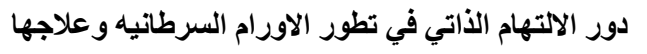

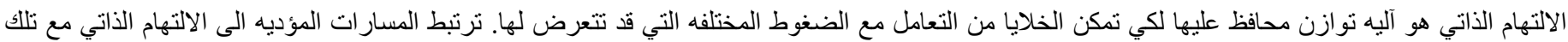

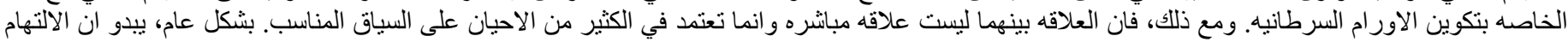

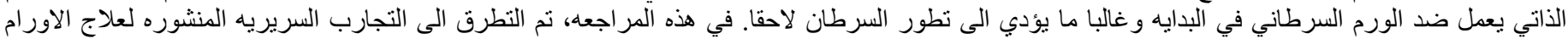

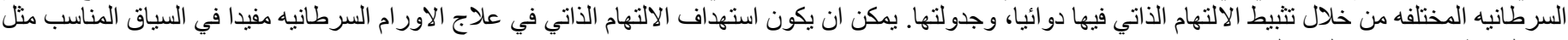
نوع السرطان ودرجته و البيئه التي يتو اجد فئها.

Corresponding author: Ismail I. Al-Janabi, Academic and Freelance Science Writer and Consultant Pharmacist, Surrey KT19 8GY, U. K.; Email: ismail.janabi@gmail.com

Article citation: Al-Janabi II. The role of autophagy in the progression and treatment of tumors. Al-Rafidain J Med Sci. 2021;1:62-71. doi: 10.54133/ajms.vli.37 


\section{INTRODUCTION}

Autophagy is a highly-conserved adaptive process by which cells can counteract the various physical, chemical and biological stresses that they are exposed to during their lifetime [1-4]. These stresses include temperature, ultraviolet light, oxygen tension, $\mathrm{pH}$, ion and metabolite concentrations, hormones, cytokines, neurotransmitters and the presence of pathogens [4]. Autophagy is a stress-resistance mechanism used by cells to keep homeostasis $[5,6]$. In this process, proteins, organelles and parts of the cytoplasm are delivered to the lysosome (in mammals) and vacuoles (in plants and yeasts) for degradation and recycling. Within tolerated stress limits, autophagy is active at basal levels to perform housekeeping functions and to preserve the energetic state of the cells [1]. However, in response to elevated stress levels such as nutrient deprivation, hypoxia, accumulation of misfolded or aggregated proteins, genotoxic factors, undersynthesis of proteins or the presence of pathogens, autophagy is upregulated to preserve cellular integrity $[7,8]$. Autophagy is regarded as an important protective mechanism because it allows cells to survive a variety of stresses while also protecting the organism from disease $[1,2,8]$. Despite the existence of various forms of autophagy, macroautophagy is the most common and best-characterized type $[9,10]$. This form of autophagy is often referred to as simply "autophagy" and will be our main focus in this review. In autophagy, the materials to be recycled (termed cargo due to their diversity) are delivered to and get digested by the lysosomes. This ultimately generates useful compounds such as amino acids, nucleosides, nucleotides, fatty acids, sugars and adenosine triphosphate (ATP) [11,12]. As such, autophagy serves two useful purposes in providing much-needed nutrients to the cells and eliminating damaged, and potentially harmful, substances. Aberrant autophagy disturbs cellular homeostasis and contributes to the development of neurodegenerative diseases and various forms of cancer $[8,11,13,14]$. Recent studies also showed the involvement of autophagy in ageing and lifespan extension in several animal model organisms and illustrated that autophagy declines with age [15-17]. The link between autophagy and cancer is like a double-edged sword. The initiation of a tumor involves the action of external and/or internal stresses acting on the cell. These stresses often lead to damaging the DNA of the cell, which could result in dysfunctional proteins, and the production of reactive oxygen species (ROS) [18-20]. If the DNA damage is left unresolved, it will pass to the next generation of cells during division, elevating the risk of tumorigenesis. Cancer cells use autophagy not only to degrade and remove damaged proteins and organelles, but also to provide themselves with the energy they require to proliferate indefinitely $[5,12]$. This side of autophagy is characterized as a pro-survival function as it promotes the existence of cancer cells. However, some evidence also points to the anti-survival role of autophagy on cancer cells and this will be discussed in detail below [20,21]. The most plausible explanation for this apparent paradox is that the breakdown and recycling of cargo through autophagy predominantly supports survival while high cellular consumption of nutrients and energy, exceeding cellular capacity, promotes cell death $[19,22]$.

\section{Induction of autophagy}

Autophagy is triggered by several intracellular and extracellular stimuli, including starvation, stress, hypoxia, ultraviolet radiation, and infection [2]. The most typical trigger of autophagy is essential nutrient starvation. Signals indicating scarcity of amino acids, insulin, and insulin growth factor are thought to converge on a master regulator protein called mammalian target of rapamycin (mTOR) (Figure 1).

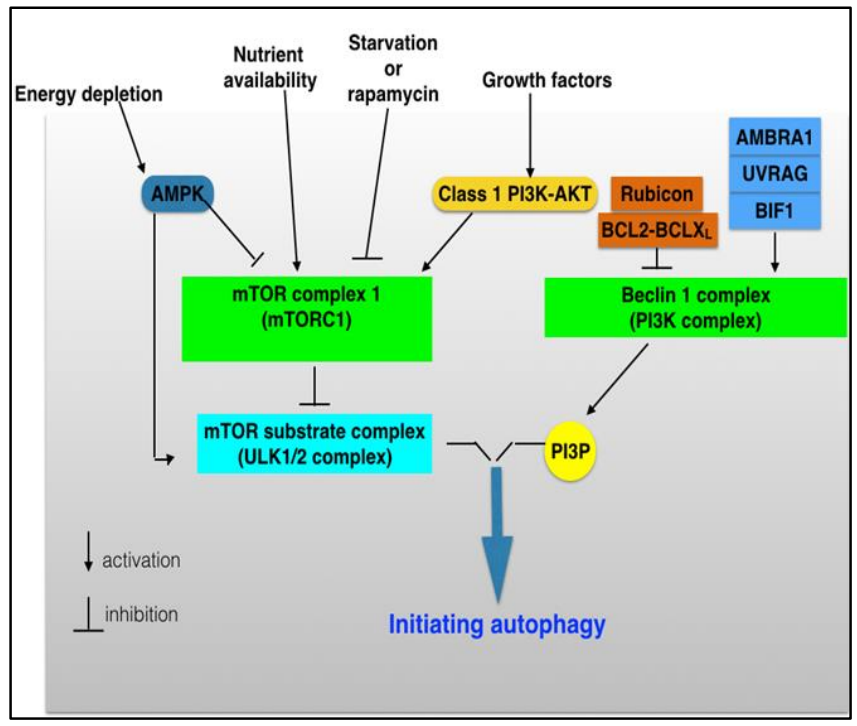

Figure 1: Induction and initiation of autophagy. AMPK: adenosine monophosphate-activated protein kinase; mTOR: mammalian target of rapamycin; mTORC1: mammalian target of rapamycin complex 1; ULK1/2: unc-51like kinase1/2; PI3K: phosphoinositide-3-kinase; AKT: also known as PKB (protein kinase B); AMBRA1: autophagy and Beclin1 regulator; UVRAG: UV radiation-resistance associated gene protein; BIf1: also known as Endophilin B1; Beclin1: also known as BECN1 (mammalian ortholog of Atg6) [23].

Indeed, treatment with inhibitors of mTOR, such as sirolimus (rapamycin), induces autophagy [23]. However, not all autophagy signals are transduced through mTOR. Moreover, factors other than amino acid and insulin signaling have been reported to be involved in autophagy, including reactive oxygen species, calcium, and adenosine monophosphateactivated protein kinase (AMPK) [22].

\section{Regulation of autophagy}

Autophagy occurs at low basal levels in virtually all cells, ensuring the availability of essential nutrients and the continuous removal of superfluous and damaged (and therefore potentially dangerous) entities $[24,25]$. The process is rapidly upregulated when cells need to generate intracellular nutrients and energy, as in the case of starvation. It is also upregulated when there is a need for the removal of damaging components, e.g. protein aggregates or infectious microorganisms, and when cells are preparing to undergo structural remodeling, such as during development [26,27]. Regulation is key to switching on autophagy for the limited time that is required. A breakthrough in our understanding of signaling pathways occurred following the identification of the mTOR protein, which modulates cell growth, cell cycle, and protein synthesis. Because of its ability to integrate disparate metabolic, nutrient, and hormonal signals, the 
mTOR signaling pathway is critical $[9,10]$. The sequestering and eventual recycling of cellular components takes place in several phases. These phases are usually categorized as initiation, nucleation, elongation, maturation and fusion. Following stress detection, a phagophore (isolation membrane) formation is induced and its likely source appears to be the endoplasmic reticulum (ER), the mitochondria or the cytoplasmic membrane. The phagophore then elongates and encapsulates the cargo within a double membrane structure, termed autophagosome. The autophagosome is eventually fused with the lysosome for the cargo to be degraded by its hydrolase enzymes. Finally, the broken down cargo is released back to the cytoplasm to be re-used $[14,28]$. Several proteins participate in the regulation of these progressive phases. A few of the genes encoding these proteins are still known by their original names when they were first discovered in yeast as simply autophagy genes (ATG) followed by a number [27]. An overview of the main regulatory signaling pathways is given below, pointing out the main players only. The process of autophagy starts with the detection of stress by the master regulator protein mTOR, which is a part of a larger protein complex called mammalian target of rapamycin complex 1 (mTORC1). With an abundance of nutrients, the complex is maintained in the active form to phosphorylate other target proteins that are important for growth. However, when the supply of nutrients is limited, mTORC1 is inactivated, thus reducing the overall protein synthesis and consequently triggering the initiation of autophagy to provide an alternative source of basic components $[25,29]$. Figure 2 depicts the roles of other major protein players, and excellent reviews on the regulation of autophagy can be found elsewhere [2,10,30].

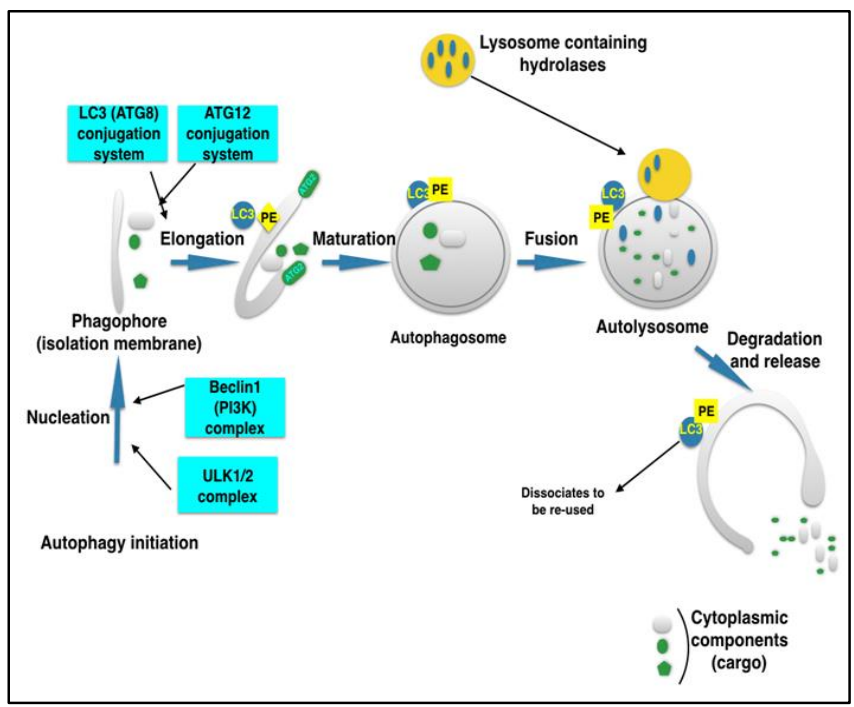

Figure 2: The different phases of autophagy and its regulation. LC3(ATG8): microtubule-associated protein1 light chain 3 (autophagy gene 8 protein); ATG12: autophagy gene 12 protein; Beclin1: also known as BECN1 (mammalian ortholog of Atg6; PI3K: phosphoinositide-3-kinase; ULK1/2: unc-51like kinase1/2; PE: phosphatidylethanolamine [30].

Once the autophagosome is formed, it fuses with the lysosome, making what is known as the autolysosome, exposing the cytoplasmic cargo to the degradative action of the acidic lysosomal hydrolase enzymes that generate the much needed recyclable materials. These materials will pour out into the cytoplasm upon the opening of the fused structure (Figure 2).

\section{AUTOPHAGY AND CANCER}

As outlined above, the main physiologic role of autophagy is the protection of cells against external and internal insults (cytoprotective role). However, in cancerous cells, autophagy may have opposing functions, being either cytoprotective or cytotoxic depending on the context. The tumor suppressor function acts as a mechanism, helping to mitigate the effects of metabolic stress and genome instability that would otherwise increase the risk of cancer initiation [19,31,32]. However, following the formation of the primary tumor, autophagy can either be cytoprotective or cytotoxic depending on the context of the cell and its microenvironment. Furthermore, and in certain patients, autophagy may contribute to chemotherapeutic resistance [33]. This dual role of autophagy appears to be paradoxical. The following sections of the review seek to address this issue with supporting studies and point to the crucial importance of understanding the role of autophagy in cancer for successful targeted therapy.

\section{The tumor-suppressor function of autophagy}

The tumor-suppressor function of autophagy has been documented through several observations. For example, the expression of the Beclin1 gene (BECN1 or ATG6), an important player in the early stages of autophagy, was found to be deleted or epigenetically silenced in up to $75 \%$ of ovarian and breast cancers and up to $40 \%$ of prostate cancers [5,34-36]. This suggests that Beclin 1 protein, the gene product of Beclin 1, may serve as a tumor suppressor [7]. Moreover, the presence of heterozygous Beclin1 (i.e. Beclin $1^{+}-$) increases the frequency of spontaneous cancers. Loss of Beclin 1 protein activity blocks activation of autophagy and precludes its protective role, resulting in impairing the removal of potentially carcinogenic agents and a profound increase in DNA damage and chromosomal abnormalities, leading to an increased risk of cancer development [7,37]. An interesting observation pointed to the fact that Beclin1 is not specifically mutated but rather lost due to the deletion of a region encompassing it on chromosome 17. That region of chromosome 17 also contains the wellknown tumor suppressor gene BRCA1 [37]. Because of the close proximity of BRCA1, it has been hypothesized that Beclin1 deletion is more of a bystander event [38]. However, the worst survival probability was associated with lower Beclin1 (but not with lower BRCA1 mRNA) expression in all breast cancer types, indicating that Beclin1 is a driver rather than a passenger gene [39]. Further observations linked other autophagy genes to cancer, e.g. Atg $4 C$ knockdown in mice was shown to increase susceptibility to developing fibrosarcoma induced by chemical agents. The Atg4 protein is highly sensitive to ROS (reactive oxygen species) and redox modifications of its cysteine residues prevent delipidation of LC3 (a microtubule-associated protein, light chain 3$)$, thereby promoting sustained autophagy $[12,21,40]$. ATG2B, ATG5, ATG9B, and ATG12 mutations have also 
been linked to gastric and colorectal cancers in humans. The autophagy gene $A T G 8$ is also frequently deleted in liver, breast, prostate and ovarian cancers and $\operatorname{Atg} 7$ conditional knockout mice develop hepatomegaly and become prone to malignant transformation [41]. Similarly, mutations in another autophagy gene, namely $U V R A G$ (ultraviolet radiation-resistance associated gene), resulted in lower autophagy activity and an increased occurrence of colorectal and gastric carcinomas. Substrates of the master autophagy regulator protein mTOR which promote cell cycle progression were also found to be implicated in carcinogenesis [2]. Autophagy also prevents tumor formation by controlling the level of ROS by the removal of damaged mitochondria. It is important to keep in mind that in all the mouse models, the inhibition of autophagy involved the embryonic deletion of the gene in the target cell. Therefore, the observations resulting from that deletion arose from cells that always suffered from the absence of that gene (and consequently impaired autophagy) and do not reflect autophagy loss at a later developmental stage, e.g. in established tumors [42]. Overall, there is strong evidence that some autophagy proteins display tumor suppression characteristics and the associated reduction in autophagy, due to the loss of function of these proteins, might lead to the initiation of oncogenesis because of the accumulation of dysfunctional organelles and proteins [18,20]. Paradoxically, cell death can also occur as a result of increasing cellular consumption due to unrestrained autophagy [19].

\section{The tumor-promoting function of autophagy}

Autophagy can also promote the survival of established tumors. As cells proliferate and the tumor grows, stressful conditions are created, manifested mainly by hypoxia and nutrient deprivation, and autophagy can assist in overcoming these stresses [20]. Deletion of Beclin1 expression, in cells forming the central zone of the tumor, enhances cell death, pointing to the paradoxical role of this autophagy protein in supporting tumor growth $[20,36,43]$. Under its physiologic function, autophagy also contributes to the survival of tumor cells by fulfilling their demands for nutrients and energy. In animal studies, metabolic stress of autophagy-deficient cells was shown to impair cell survival in animal studies [9]. Therefore, autophagy, from this point of view, contributes to survival and growth by enhancing stress tolerance and meeting the metabolic and energetic demands of fast-growing tumor cells. In this setting, inhibiting autophagy genes can lead to tumor shrinkage. Several studies [44-47] have found that mutations activating the canonical RAS (rat sarcoma) oncogene increase autophagy, promote tumor growth, and are associated with a poor prognosis of colon, lung, and pancreatic cancers. The interplay between cancer and autophagy will be discussed below in the context of the relevant hallmarks of tumorigenesis.

\section{AUTOPHAGY AND PROGRAMMED CELL DEATH (APOPTOSIS)}

Autophagy and apoptosis are two mechanisms by which cells, including tumor cells, respond to different stresses to maintain homeostasis. Although these two processes act antagonistically, their crosstalk under specified biological conditions can lead to cooperation and cell death [48-51]. Key regulators are shared by autophagy and apoptosis and the impact of these regulators on the early stages of carcinogenesis is considered below. Beclin1 is an important protein in the regulation of the early stages of autophagy. However, in addition, Beclin1 is also implicated in apoptosis, thus representing a link between the two mechanisms. In vitro overexpression of Beclin1 in gastric cancer or glioblastoma cell lines induces apoptosis upon exposure to cytotoxic agents [52]. It is possible that during the early stages of cancer, Beclin1 induces both autophagy and apoptosis. Members of the ATG5-ATG12-ATG16 complex of proteins are also involved in the interplay between autophagy and apoptosis. Yoo et al demonstrated that exogenous expression of ATG12 in RAS-transfected intestinal epithelial cells resulted in decreased proliferation and increased cell death [53]. Furthermore, an in vitro study in which HeLa cells (laboratory cells exhibiting tumorigenesis) were treated with IFN(interferon-gamma, a cytokine) shows that death is dependent on the expression of ATG5 and its interaction with the appropriate death receptor on the cell's surface [54]. These studies point to the participation of the ATG5-ATG12ATG16 in the induction of autophagy and activation of apoptosis during the early stages of tumor development. The well-known tumor suppressor protein TP53 (often known as p53) is another key modulator linking autophagy with apoptosis. It is the master intracellular sensor of stress caused by genotoxic agents or oncogenes. Cellular insults cause localization of TP53 to the nucleus where it upregulates transcription of a distinct set of genes involved in cell cycle control, DNA-damage repair, apoptosis and autophagy [55]. The cell cycle arrest and apoptosis mediated by TP53, during the early stages of tumor development in autophagy-defective cells, limits tumor growth. It appears that, during the early stages of tumor development, autophagy and apoptosis cooperate to prevent damage caused by carcinogenic stimuli and to remove damaged cells. The link between autophagy and apoptosis does not remain at the same steady level during the progression of a tumor. Instead, it is modified by external and internal factors influencing both processes.

\section{AUTOPHAGY AND METABOLIC PROGRAMMING IN CANCER}

For cancer cells to survive and adapt, they need to establish changes to their metabolic pathways to support the fast proliferation, migration, and other features essential for malignancy. Tumor cells achieve this by switching their metabolic utilization of glucose from the usual oxidative phosphorylation to glycolysis [56,57]. This will ensure a steady supply of energy in the form of ATP (albeit less efficiently) and the various macromolecular building blocks. Otto Warburg was the first author to identify changes in the metabolism of cancer cells [57]. He demonstrated that cancer cells consume large amounts of glucose and correspondingly excrete high amounts of lactate even when in the presence of oxygen. This was later termed the Warburg effect or aerobic glycolysis. This pathway of producing energy from glucose was thought to be less advantageous considering the reduced 
amount of ATP produced from a single molecule of glucose in comparison with oxidative phosphorylation. Nevertheless, the Warburg effect occurs independently of oxygen and can be utilized in the hypoxic zones of a tumor. Moreover, the Warburg effect generates the much-needed building blocks for other metabolic pathways [57,58]. The transformation of cancer cells to aerobic glycolysis requires the activation of oncogenes such as RAS, MYC (from myelocytomatosis) and AKT (known as PKB, protein kinase B) and the inhibition of tumor suppressor genes such as p53 [59,60]. Autophagy supports this metabolic transformation through the provision of a wide variety of biomolecules. For example, monosaccharides, being the breakdown products of carbohydrates, can be used to fuel glycolysis, while the amino acids and fatty acids, being the autophagic breakdown products of proteins and fats respectively, can provide the substrates needed for the TCA (tricarboxylic acid) cycle, also known as the Krebs cycle, for example [56]. Hypoxic zones in tumors, where oxygen levels fall below $2 \%$, trigger mechanisms to maintain homeostasis. The HIF-1 (hypoxiainducible factor 1) protein is the primary sensor in the maintenance of homeostasis relating to the lack of oxygen in tissues. HIF-1 induces autophagy through pathways that eventually converge on the stimulation of Beclin1 or the inhibition of mTOR. Furthermore, HIF-1 also induces mitochondrial autophagy (mitophagy) through the release of Beclin1. Autophagy is also required in cancer cells to provide amino acids and fatty acid substrates derived from protein and fat degradation, respectively $[61,62]$.

\section{AUTOPHAGY AND METASTASIS}

Metastasis, a stage following the establishment of a primary tumor, is the cause of death of most cancer patients [63]. The incessant proliferation of cancer cells creates a microenvironment lacking oxygen and nutrients, which drives cancer cells to migrate in search of better niches. Evidence also exists of limited migration of cancer cells during the early stages of tumor development, but metastasis is usually associated with the advanced stages of carcinogenesis [7]. Detachment of cells from the primary tumor, intravasation, survival in blood or lymph, extravasation, settlement, and colonization of the secondary site are all steps in the metastasis cascade [64]. Autophagy plays an essential role in this cascade, albeit with contradictory overall influence. A few reports show that autophagy favors metastasis $[65,66]$, while others point out that autophagy inhibits cancer cell metastasis $[67,68]$. However, this may be expected considering the complexity of events involved in the metastasis cascade. With a process this complex, it is better to elucidate the function of autophagy in a particular stage in the hope of targeting that step for therapeutic gain. The process of metastasis begins with the detachment of cells from their primary mass and the activation of the epithelialmesenchymal transition (EMT) program the details of this program are beyond the scope of this review $\}$. This event triggers a certain type of cell death called anoikis, which occurs when cells are detached from the extracellular matrix (ECM) [7]. The interactions between cells and the ECM require complex bonds called focal adhesion (FA), which are essential for homeostasis [69]. Metabolic stress within the tumor microenvironment activates autophagy, which degrades essential components of FA, leading to the activation of cell motility. Tumor cells utilize activated autophagy to overcome anoikis and become resistant to dying by this route in favor of cell motility and metastasis. Fung et al discovered that tumor cells that shed ECM induce autophagy, which helps these cells avoid anoikis [70]. Also, detachment of hepatocellular carcinoma cells from the ECM resulted in the inactivation of the $\mathrm{mTORC} 1$ complex, thus leading to enhanced autophagy and avoiding anoikis [71]. Another molecule that activates autophagy and induces resistance to anoikis is miR-30a. Inhibition of this microRNA (miRNA) results in a decrease in Beclin1 and ATG5 and an increase in cell death [72]. Following survival against various challenges during their journey to their target metastatic organ, tumor cells must now adapt to their new microenvironment. This new microenvironment could be distinctly different from that which they left behind. The new organ may have different ECM composition, oxygen and nutrient levels. If these arriving cells do not adapt, they may enter a state of dormancy and remain clinically undetectable for a long time [73]. However, their eventual exit from dormancy can cause the often encountered tumor relapse. Autophagy helps these dormant cells to remain viable as they stay in the G0-G1 phases of the cell cycle. Green et al demonstrated that inhibition of autophagy in dormant cells of mouse breast cancer models decreased their viability and ability to form metastasis [74]. When the newly arrived cells do adapt to the new environment, they usually exhibit a highly flexible metabolism. For example, metastatic cells colonizing the lungs might upregulate the expression of antioxidant responses to cope with the oxidative nature of this organ. If these defenses fail, then the accumulation of ROS in these metastatic cells triggers autophagy. Peng et al showed that the lungs, to which primary liver tumor cells have metastasized, exhibited a higher level of autophagy compared to their initial site and that genetic inhibition of autophagy in the highly metastatic liver cancer cells blocked their colonization potential without changing EMT activation, invasion and migration [75].

\section{AUTOPHAGY AND IMMUNE RESPONSE AGAINST CANCER}

The immune system plays a vital role in the prevention of tumor initiation, progression, metastasis and the response to anticancer therapies [76-78]. Through the surveillance of this system, tumor cells can be recognized and eliminated [79]. When considering the influence of autophagy on the immune response to cancer, the local tumor environment has to be taken into consideration [80]. This is important as the tumor microenvironment (TME) can impact cancer progression through its various constituents. The TME consists not only of the proliferating tumor cells themselves but of several other cell types, including immune cells, in addition to the secreted proteins. Understanding how the various components of TME influence tumor progression and the impact of autophagy is at its infancy. A simple summary is presented below concerning the involvement of autophagy in the immune response to the 
presence of a tumor in the body with an illustrative diagram in Figure 3.

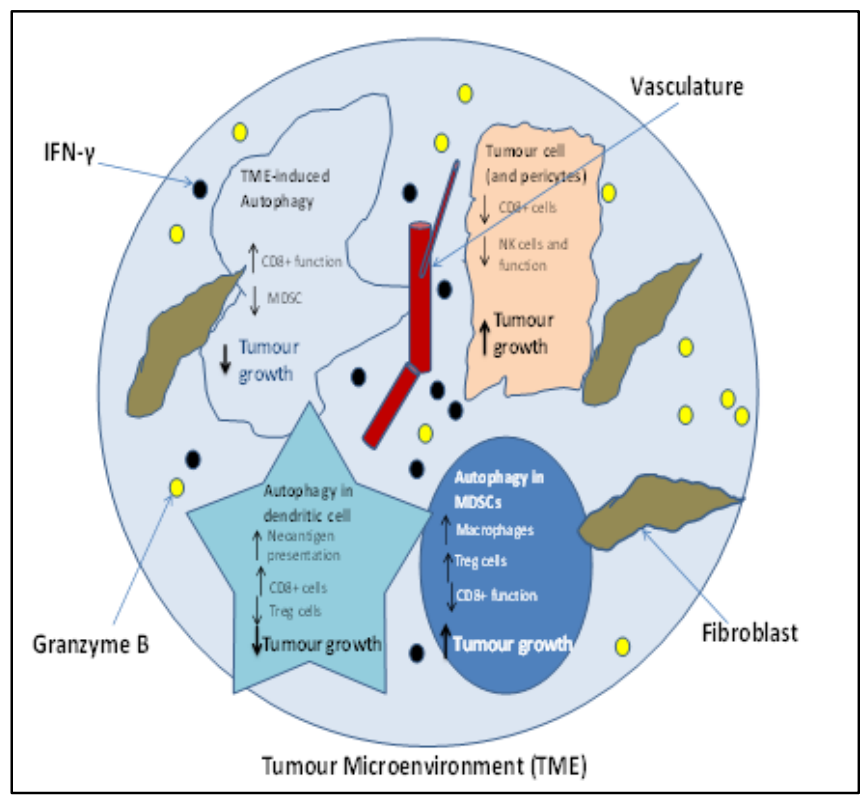

Figure 3: A schematic diagram of the tumor microenvironment (TME) illustrating the influence of autophagy on its various components and the outcome on cancer progression. IFN- $\gamma$ : interferon gamma; MDSCs: myeloidderived suppressor cells; Tregs: T-regulatory cells; NK: natural killer [80].

The adaptive immune response to tumors is triggered by the neoantigen (resulting from the breakdown of dysfunctional proteins made by cancer cells) presented by dendritic cells (DCs) to naïve T cells via MHC (major histocompatibility complex) and the subsequent induction of effector $\mathrm{T}$ cells. Effective neoantigen presentation and the consequent response of effector $\mathrm{T}$ cells are essential factors for $\mathrm{a}$ successful immune response to a growing tumor. Reduction of $\mathrm{MHC}$ expression and the presentation of dysfunctional epitopes are just two mechanisms of evading detection by immune surveillance that are frequently encountered in different types of cancers. Activation of autophagy in DCs may improve their function in presenting neoantigens to $\mathrm{T}$ cells $[81,82]$. The conjugation of antigen to activators, to stimulate DCs, was shown to trigger an antitumor response in mice through an autophagy-dependent mechanism [83]. Autophagy can also create new epitopes which could increase immune recognition [84]. Therefore, when viewed from this angle, autophagy appears to be associated with efficient antigen presentation by DCs and acts to inhibit tumor progression. However, in different contexts, autophagy may play a negative role in neoantigen presentation, thus facilitating immune evasion. For example, PDAC (pancreatic ductal adenocarcinoma) cells display a low level of MHCI and the knockdown of the NBR1 (neighbor of BRCA1) gene increases MHCI expression, confirming the implication of autophagy as NBRl functions as an autophagy cargo receptor gene. The use of autophagy inhibitors restored the expression of MHCI and led to a reduction in tumor growth [85]. Metabolites and cytokines of TME can themselves modulate the autophagy of nearby cells and influence the immune response. For example, interferon-gamma (IFN- $\gamma$ ) can induce autophagy in gastric cancer cells and inhibit tumor growth
[86]. Furthermore, metabolic disorders such as glycolysis hypoxia in TME components can be stressful enough to induce autophagy in local cells. Autophagy can be induced in $\mathrm{T}$ cells exposed to elevated potassium levels to augment the persistence of these T-cells in TME and the consequent tumor regression. Moreover, the increased glycolysis activity of TME appears to enrich it with myeloid-derived suppressor cells (MDSCs), which function as suppressors of $\mathrm{T}$ effector cells as seen in triple-negative breast cancer [87]. Autophagy can also inhibit the immune response, enhancing cancer's ability to evade immune surveillance and thus facilitate tumor growth. MDSCs are components of the immunosuppressive compartment of TME and their autophagy has been associated with $\mathrm{T}$-cell function impairment and regulatory $\mathrm{T}$ cells (Tregs) recruitment [88-90]. An increase in autophagy flux was observed in MSDCs collected from melanoma patients and taken as an indication that these myeloid cells play an immunosuppressive role in TME favoring tumor growth.

\section{AUTOPHAGY IN THE TREATMENT OF TUMORS}

Clinical efforts to inhibit autophagy in cancer therapy have focused mainly on the use of chloroquine (CQ) and hydroxychloroquine (HCQ). The long-term clinical history of these two molecules in treating a variety of diseases, as well as their affordability, make them the autophagy inhibitors of choice. However, in more recent years, more potent alternatives have emerged, including Lys05 and DQ661, and the results of their clinical use are still to be published [91]. Owing to the context-driven role of autophagy in cancer, its systemic inhibition can give rise to variable effects on different organs or tissues. Therefore, the therapeutic focus of manipulating autophagy in the treatment of tumors has been mainly to augment, and/or lower the resistance to, other anticancer medicines [6,24,92,93]. During the advanced stages of cancer, chemoresistance becomes the main obstacle to successful treatment. Chemotherapy-induced stress can induce autophagy and have a cytoprotective effect, allowing tumor cells to resist chemotherapy $[31,94]$. Cisplatin, a wellknown chemotherapeutic compound, can induce autophagy by upregulating the expression of the Beclin1 gene [95]. In one study, the induction of autophagy by TRP14 (thioredoxinlike protein) lowers sensitivity to Cisplatin in ovarian cancer cell lines, and when TRP14 expression was inhibited, the sensitivity to Cisplatin was markedly reversed [94]. Other studies have demonstrated similar effects, showing that autophagy acts to protect tumor cells against chemotherapeutic agents [96,97]. Occasional contradictory results were also reported during the inhibition of autophagy with certain targeted therapies. Li et al showed that the death of cancer cells may be achieved by the activation of autophagy, using the mTOR inhibitor Rapamycin, in cancer cells treated with Cetuximab [98]. Results from clinical trials published until 2020 where the autophagic flux was evaluated are given in Table 1 [91]. The presence of autophagy is usually assessed from measurements of vesicle accumulation in peripheral blood mononuclear cells (PBMCs) and serial tumor biopsies. A first glance at the information displayed in Table 1 reveals that only HCQ was used as an autophagy 
inhibitor in these published clinical trials. However, CQ was also used in other published trials but without practical assessment of autophagy and therefore these trials were left out from Table 1. Concerning Table 1, HCQ showed limited clinical responses as a single agent in metastatic pancreatic ductal adenocarcinoma (PDAC). Monotherapy with HCQ showed inconsistent inhibition of autophagy and resulted in negligible therapeutic efficacy [99]. Although the study of the combination of HCQ and Erlotinib was mainly concerned with the collection of toxicity data, it did suggest a clinical benefit for this therapy in a subset of cancer patients [100]. Dose-limited toxicity hindered the achievement of consistent autophagy and the significant improvement in overall survival when HCQ was given in combination with Temozolomide and radiotherapy [101]. Two out of six patients with refractory BRAF (a proto-oncogene) wild-type melanoma had a near-complete response upon the administration of HCQ and Temozolomide [102]. Vogl et al concluded that the combination of HCQ and Bortezomib is a feasible and potentially useful strategy for improving outcomes in myeloma [103]. Similarly, HCQ and the mTOR inhibitor Temsirolimus yielded significant antitumor activity [104].
The preliminary efficacy results of the combination of HCQ and the histone deacetylase inhibitor Vorinostat were also encouraging to necessitate the planning of further studies [105]. The study conducted by Chi et al was interesting as it used an autophagy inhibitor (HCQ) together with an autophagy inducer (Sirolimus) and found that the response obtained, without tumor volume reduction, may indicate that non-proliferation glycolysis occurred mainly in cancerassociated fibroblasts [106]. The combination therapy of HCQ and Gemcitabine, a chemotherapeutic anti-metabolite agent, yielded clinically significant results in that $61 \%$ of patients had a decrease in CA19-9, a surrogate biomarker for cancer, following treatment, with $50 \%$ of patients demonstrating a reduction of $\geq 50 \%$ [107]. This reduction in CA19-9 was greater than expected with a single cycle of Gemcitabine treatment. As mentioned earlier, the main aim of the trials mentioned in Table 1 was not to elucidate treatment response but to investigate the toxicity and establish mechanisms. Nevertheless, the response of the tumor to the combination therapy was recorded as a secondary endpoint and the results were found clinically encouraging and warranted pursuing further.

Table 1: Cancer clinical trials employing the autophagy inhibitor HCQ pre-2020 where the autophagy influx was followed.

\begin{tabular}{|c|c|c|c|c|c|}
\hline $\begin{array}{l}\text { Autophagy } \\
\text { inhibitor }\end{array}$ & $\begin{array}{l}\text { In conjunction } \\
\text { with }\end{array}$ & Tumor type & $\begin{array}{l}\text { Clinical trial } \\
\text { phase }\end{array}$ & Clinical outcomes & Reference \\
\hline HCQ & None & $\begin{array}{l}\text { Metastatic } \\
\text { PDAC }\end{array}$ & II & $\begin{array}{l}\text { Median PFS }=46 \text { days } \\
\text { Overall survival }=69 \text { days }\end{array}$ & 99 \\
\hline $\mathrm{HCQ}$ & $\begin{array}{l}\text { Temozolomide } \\
\text { and radiation }\end{array}$ & Glioblastoma & I and II & $\begin{array}{l}\text { Median survival }=15.6 \text { months with } \\
\text { survival rates at } 12,18 \text { and } 24 \text { months of } \\
70 \%, 36 \% \text { and } 25 \% \text { respectively. }\end{array}$ & 101 \\
\hline HCQ & Temozolomide & Melanoma & I & $\mathrm{PR}=14 \%$ and $\mathrm{SD}=27 \%$ & 102 \\
\hline HCQ & Vorinostat & Solid tumor & I & $\begin{array}{l}\text { One patient with renal carcinoma had } \\
\text { durable PR and two patients with CRC } \\
\text { had prolonged SD }\end{array}$ & 105 \\
\hline HCQ & $\begin{array}{c}\text { Sirolimus } \\
\text { (Rapamycin) }\end{array}$ & Sarcoma & Case series & $\mathrm{PR}=60 \%, \mathrm{SD}=30 \%$ and $\mathrm{PD}=10 \%$ & 106 \\
\hline HCQ & Gemcitabine & PDAC & I and II & $\begin{array}{l}61 \% \text { had a decrease in CA } 19-9 \text { and } 50 \% \\
\text { demonstrated } \geq 50 \% \text { reduction in CA } 19-9\end{array}$ & 107 \\
\hline
\end{tabular}

Abbreviations: HCQ: hydroxychloroquine; NSCLC: non-small cell lung carcinoma; PDAC: pancreatic ductal adenocarcinoma; PFS: progression-free survival; PR: partial response; SD: stable disease; CRC: colorectal cancer; CA19-9: level of protein called CA19-9 in blood. 


\section{Concluding remarks}

Understanding the role of autophagy in tumorigenesis is still a developing field. Manipulating autophagy for induction of cell death and its inhibition through exploring contextdependent mechanisms can have therapeutic benefits. Needless to say, normal cells should not be affected while manipulating autophagy as a basal level of this process is required for cell function.

\section{Conflicting interests}

Nothing declared.

\section{Data sharing statement}

N/A

\section{REFERENCES}

1. Levine B, Kroemer G. Autophagy in the pathogenesis of disease. Cell. 2008;132(1):27-42. doi: 10.1016/j.cell.2007.12.018.

2. Khandia R, Dadar M, Munjal A, Dhama K, Karthik K, Tiwari R, et al. A comprehensive review of autophagy and its various roles in infectious, non-Infectious, and lifestyle diseases: current knowledge and prospects for disease prevention, novel drug design, and therapy. Cells.2019;8(7):674 doi:10.3390/cells8070674

3. Kawabata T, Yoshimori T. Autophagosome biogenesis and human health. Cell Discov. 2020;6:33. doi: 10.1038/s41421-020-0166-y.

4. Kroemer G, Mariño G, Levine B. Autophagy and the integrated stress response. Mol Cell. 2010;40(2):280-293. doi 10.1016/j.molcel.2010.09.023.

5. Amaravadi RK, Kimmelman AC, Debnath J. Targeting autophagy in cancer: recent advances and future directions. Cancer Discov. 2019;9(9):1167-1181; doi: 10.1158/2159-8290.CD-19-0292.

6. Lim J, Murthy A. Targeting autophagy to treat cancer: challenges and opportunities. Front Pharmacol. 2020;11:590344. doi: 10.3389/fphar.2020.590344.

7. Chavez-Dominguez R, Perez-Medina M, Lopez-Gonzalez JS, GaliciaVelasco M, Aguilar-Cazares D. The double-edge sword of autophagy in cancer: from tumor suppression to pro-tumor activity. Front Oncol. 2020;10:578418. doi: 10.3389/fonc.2020.578418.

8. Ichimiya T, Yamakawa T, Hirano T, Yokoyama Y, Hayashi Y, Hirayama $\mathrm{D}$, et al. Autophagy and autophagy-related diseases: a review. Int $\mathrm{J} \mathrm{Mol}$ Sci. 2020;21(23):8974. doi: 10.3390/ijms21238974.

9. Boya P, Reggiori F, Codogno P. Emerging regulation and functions of autophagy. Nat Cell Biol. 20131;15(7):713-720. doi: 10.1038/ncb2788.

10. Ravikumar B, Sarkar S, Davies JE, Futter M, Garcia-Arencibia M, GreenThompson ZW, et al. Regulation of mammalian autophagy in physiology and pathophysiology. Physiol Rev. 2010;90(4):1383-1435. doi: 10.1152/physrev.00030.2009.

11. Dikic I, Elazar Z. Mechanism and medical implications of mammalian autophagy. Nat Rev Mol Cell Biol. 2018;19(6):349-364. doi: 10.1038/s41580-018-0003-4.

12. Santana-Codina N, Mancias JD, Kimmelman AC. The role of autophagy in cancer. Annu Rev Cancer Biol. 2017;1:19-39. doi: 10.1146/annurevcancerbio-041816-122338.

13. Kawabata T, Yoshimori T. Autophagosome biogenesis and human health. Cell Discov. 2020;6(1):33. doi: 10.1038/s41421-020-0166-y.

14. Choi AM, Ryter SW, Levine B. Autophagy in human health and disease. N Engl J Med. 2013;368(7):651-662. doi: 10.1056/NEJMra1205406.

15. Aman Y, Schmauck-Medina T, Hansen M, Morimoto RJ, Simon AK, Bjedor I, et al. Autophagy in healthy aging and disease. Nat Aging. 2021;1:634-650. doi: 10.1038/s43587-021-00098-4.
16. Leidal AM, Levine B, Debnath J. Autophagy and the cell biology of agerelated disease. Nat Cell Biol. 2018;20(12):1338-1348. doi: 10.1038/s41556-018-0235-8.

17. Kirkin V. History of the selective autophagy research: how did it begin and where does it stand today? J Mol Biol. 2020;432(1):3-27. doi: 10.1016/j.jmb.2019.05.010

18. Panda PK, Mukhopadhyay S, Das DN, Sinha N, Naik PP, Bhutia SK. Mechanism of autophagic regulation in carcinogenesis and cancer therapeutics. Semin Cell Dev Biol. 2015;39:43-55. doi: 10.1016/j.semcdb.2015.02.013.

19. Mathew R, Karantza-Wadsworth V, White E. Role of autophagy in cancer. Nat Rev Cancer. 2007;7(12):961-967. doi: 10.1038/nrc2254.

20. Yun CW, Lee SH. The roles of autophagy in cancer. Int $J$ Mol Sci. 2018;19(11):3466. doi: 10.3390/ijms19113466.

21. White E. The role for autophagy in cancer. J Clin Invest. 2015;125(1):4246. doi: 10.1172/JCI73941.

22. Mizushima N. Autophagy: process and function. Genes Dev. 2007;21(22):2861-2873. doi: 10.1101/gad.1599207.

23. Lin X, Han L, Weng J, Wang K, Chen T. Rapamycin inhibits proliferation and induces autophagy in human neuroblastoma cells. Biosci Rep. 2018;38(6):BSR20181822. doi: 10.1042/BSR20181822.

24. Rebecca VW, Amaravadi RK. Emerging strategies to effectively target autophagy in cancer. Oncogene. 2016;35(1):1-11. doi: 10.1038/onc.2015.99.

25. Kundu M, Thompson CB. Autophagy: basic principles and relevance to disease. Аnпи Rev Pathol. 2008;3:427-455. doi: 10.1146/annurev.pathmechdis.2.010506.091842. PMID: 18039129.

26. Levine B, Klionsky DJ. Autophagy wins the 2016 Nobel prize in physiology or medicine breakthroughs in baker's yeast fuel advances in biomedical research. Proc Natl Acad Sci U S A. 2017;114(2):201-205. doi: $10.1073 /$ pnas. 1619876114

27. Levine B, Kroemer G. Biological functions of autophagy genes: A disease perspective. Cell. 2019;176(1-2):11-42. doi: 10.1016/j.cell.2018.09.048.

28. Li X, He S, Ma B. Autophagy and autophagy-related proteins in cancer. Mol Cancer. 2020;19(1):12. doi: 10.1186/s12943-020-1138-4.

29. Botti J, Djavaheri-Mergny M, Pilatte Y, Codogno P. Autophagy signaling and the cogwheels of cancer. Autophagy. 2006;2(2):67-73. doi: 10.4161/auto.2.2.2458

30. He C, Klionsky DJ. Regulation mechanisms and signaling pathways of autophagy. Annu Rev Genet. 2009;43:67-93. doi: 10.1146/annurevgenet-102808-114910.

31. Gewirtz DA. The four faces of autophagy: implications for cancer therapy. Cancer Res. 2014;74(3):647-651. doi: 10.1158/00085472.CAN-13-2966.

32. Folkerts H, Hilgendorf S, Vellenga E, Bremer E, Wiersma VR. The multifaceted role of autophagy in cancer and the microenvironment. Med Res Rev. 2019;39(2):517-560. doi: 10.1002/med.21531.

33. Pérez-Hernández M, Arias A, Martínez-García D, Pérez-Tomás R, Quesada R, Soto-Cerrato V. Targeting autophagy for cancer treatment and tumor chemosensitization. Cancers (Basel). 2019;11(10):1599. doi: $10.3390 /$ cancers 11101599 .

34. Lorin S, Hamaï A, Mehrpour M, Codogno P. Autophagy regulation and its role in cancer. Semin Cancer Biol. 2013;23(5):361-379. doi: 10.1016/j.semcancer.2013.06.007.

35. White E. Deconvoluting the context-dependent role for autophagy in cancer. Nat Rev Cancer. 2012;12(6):401-410. doi: 10.1038/nrc3262.

36. White E, DiPaola RS. The double-edged sword of autophagy modulation in cancer. Clin Cancer Res. 2009;15(17):5308-5316. doi: 10.1158/1078-0432.CCR-07-5023.

37. Vega-Rubín-de-Celis S. The role of Beclin1-dependent autophagy in cancer. Biology (Basel). 2019;9(1):4. doi: 10.3390/biology9010004. 
38. Laddha SV, Ganesan S, Chan CS, White E. Mutational landscape of the essential autophagy gene BECN1 in human cancers. Mol Cancer Res. 2014;12(4):485-490. doi: 10.1158/1541-7786.MCR-13-0614

39. Wijshake T, Zou Z, Chen B, Zhong L, Xiao G, Xie Y, Doench, et al. Tumor-suppressor function of Beclin 1 in breast cancer cells requires E-cadherin. Proc Natl Acad Sci U S A. 2021;118(5):e2020478118. doi: 10.1073/pnas.2020478118.

40. Fu Y, Huang Z, Hong L, Lu JH, Feng D, Yin XM, et al. Targeting ATG4 in cancer therapy. Cancers (Basel). 2019;11(5):649. doi: 10.3390/cancers 11050649 .

41. Levine B. Cell biology: autophagy and cancer. Nature. 2007;446(7137):745-747. doi: 10.1038/446745a.

42. Rosenfeldt MT, Ryan KM. The role of autophagy in tumor development and cancer therapy. Expert Rev Mol Med. 2009;11:e36. doi:10.1017/S1462399409001306.

43. Degenhardt K, Mathew R, Beaudoin B, Bray K, Anderson D, Chen G, et al Autophagy promotes tumor cell survival and restricts necrosis, inflammation, and tumorigenesis. Cancer Cell. 2006;10(1):51-64. doi: 10.1016/j.ccr.2006.06.001.

44. Guo JY, Chen HY, Mathew R, Fan J, Strohecker AM, Karsli-Uzunbas G, et al. Activated Ras requires autophagy to maintain oxidative metabolism and tumorigenesis. Genes Dev. 2011;25(5):460-470. doi: 10.1101/gad.2016311.

45. Karnoub AE, Weinberg RA. Ras oncogenes: split personalities. Nat Rev Mol Cell Biol. 2008;9(7):517-531. doi: 10.1038/nrm2438.

46. Goel S, Huang J, Klampfer L. K-Ras, intestinal homeostasis and colon cancer. Curr Clin Pharmacol. 2015;10(1):73-81. doi: 10.2174/1574884708666131111204440.

47. Masliah-Planchon J, Garinet S, Pasmant E. RAS-MAPK pathway epigenetic activation in cancer: miRNAs in action. Oncotarget 2016;7(25):38892-38907. doi: 10.18632/oncotarget.6476.

48. Bhutia SK, Mukhopadhyay S, Sinha N, Das DN, Panda PK, Patra SK, et al. Autophagy: cancer's friend or foe? Adv Cancer Res. 2013;118:6195. doi: 10.1016/B978-0-12-407173-5.00003-0.

49. Baehrecke EH. Autophagy: dual roles in life and death? Nat Rev Mol Cell Biol. 2005;6(6):505-510. doi: 10.1038/nrm1666.

50. Mukhopadhyay S, Panda PK, Sinha N, Das DN, Bhutia SK. Autophagy and apoptosis: where do they meet? Apoptosis. 2014;19(4):555-566. doi: 10.1007/s10495-014-0967-2.

51. Denton D, Kumar S. Autophagy-dependent cell death. Cell Death Differ. 2019;26(4):605-616. doi: 10.1038/s41418-018-0252-y.

52. Su M, Mei Y, Sinha S. Role of the crosstalk between autophagy and apoptosis in cancer. $J$ Oncol. 2013;2013:102735. doi: $10.1155 / 2013 / 102735$

53. Yoo BH, Khan IA, Koomson A, Gowda P, Sasazuki T, Shirasawa S, et al. Oncogenic RAS-induced downregulation of ATG12 is required for survival of malignant intestinal epithelial cells. Autophagy. 2018;14(1):134-151. doi: 10.1080/15548627.2017.1370171.

54. Pyo JO, Jang MH, Kwon YK, Lee HJ, Jun JI, Woo HN, et al. Essential roles of Atg5 and FADD in autophagic cell death: dissection of autophagic cell death into vacuole formation and cell death. $J$ Biol Chem. 2005;280(21):20722-20729. doi: 10.1074/jbc.M413934200.

55. Balaburski GM, Hontz RD, Murphy ME. p53 and ARF: unexpected players in autophagy. Trends Cell Biol. 2010;20(6):363-369. doi: 10.1016/j.tcb.2010.02.007.

56. Rabinowitz JD, White E. Autophagy and metabolism. Science. 2010;330(6009):1344-1348. doi: 10.1126/science.1193497.

57. Kimmelman AC, White E. Autophagy and tumor metabolism. Cell Metab. 2017;25(5):1037-1043. doi: 10.1016/j.cmet.2017.04.004.
58. Poillet-Perez L, White E. Role of tumor and host autophagy in cancer metabolism. Genes Dev. 2019;33(11-12):610-619. doi: 10.1101/gad.325514.119.

59. Gordan JD, Thompson CB, Simon MC. HIF and c-Myc: sibling rivals for control of cancer cell metabolism and proliferation. Cancer Cell. 2007;12(2):108-113. doi: 10.1016/j.ccr.2007.07.006

60. Kawauchi K, Araki K, Tobiume K, Tanaka N. p53 regulates glucose metabolism through an IKK-NF-kappaB pathway and inhibits cell transformation. Nat Cell Biol. 2008;10(5):611-618. doi $10.1038 / \mathrm{ncb} 1724$

61. Semenza GL. HIF-1: upstream and downstream of cancer metabolism. Curr Opin Genet Dev. 2010;20(1):51-56. doi: 10.1016/j.gde.2009.10.009.

62. Pezzuto A, Carico E. Role of HIF-1 in cancer progression: novel insights A review. Curr Mol Med. 2018;18(6):343-351. doi: 10.2174/1566524018666181109121849.

63. Dillekås H, Rogers MS, Straume O. Are $90 \%$ of deaths from cancer caused by metastases? Cancer Med. 2019;8(12):5574-5576. doi: $10.1002 /$ cam 4.2474

64. Mowers EE, Sharifi MN, Macleod KF. Autophagy in cancer metastasis. Oncogene. 2017;36(12):1619-1630. doi: 10.1038/onc.2016.333.

65. Yazdani HO, Huang H, Tsung A. Autophagy: dual response in the development of hepatocellular carcinoma. Cells. 2019;8(2):91. doi: $10.3390 /$ cells 8020091

66. Dower CM, Wills CA, Frisch SM, Wang HG. Mechanisms and context underlying the role of autophagy in cancer metastasis. Autophagy. 2018;14(7):1110-1128. doi: 10.1080/15548627.2018.1450020.

67. Maroni P, Bendinelli P, Resnati M, Matteucci E, Milan E, Desiderio MA The autophagic process occurs in human bone metastasis and implicates molecular mechanisms differently affected by rab5a in the early and late stages. Int J Mol Sci. 2016;17(4):443. doi: 10.3390/ijms17040443.

68. Su Z, Yang Z, Xu Y, Chen Y, Yu Q. Apoptosis, autophagy, necroptosis, and cancer metastasis. Mol Cancer. 2015;14:48. doi: 10.1186/s12943015-0321-5.

69. Nagano M, Hoshino D, Koshikawa N, Akizawa T, Seiki M. Turnover of focal adhesions and cancer cell migration. Int $J$ Cell Biol. 2012;2012:310616. doi: 10.1155/2012/310616.

70. Fung C, Lock R, Gao S, Salas E, Debnath J. Induction of autophagy during extracellular matrix detachment promotes cell survival. Mol Biol Cell. 2008;19(3):797-806. doi: 10.1091/mbc.e07-10-1092.

71. Sun L, Li T, Wei Q, Zhang Y, Jia X, Wan Z, et al. Upregulation of BNIP3 mediated by ERK/HIF-1 $\alpha$ pathway induces autophagy and contributes to anoikis resistance of hepatocellular carcinoma cells. Future Oncol. 2014;10(8):1387-1398. doi: 10.2217/fon.14.70.

72. Gozuacik D, Akkoc Y, Ozturk DG, Kocak M. Autophagy-regulating microRNAs and cancer. Front Oncol. 2017;7:65. doi: $10.3389 /$ fonc. 2017.00065

73. Schild T, Low V, Blenis J, Gomes AP. Unique metabolic adaptations dictate distal organ-specific metastatic colonization. Cancer Cell. 2018;33(3):347-354. doi: 10.1016/j.ccell.2018.02.001.

74. Vera-Ramirez L, Vodnala SK, Nini R, Hunter KW, Green JE. Autophagy promotes the survival of dormant breast cancer cells and metastatic tumor recurrence. Nat Commun. 2018;9(1):1944. doi: 10.1038/s41467018-04070-6.

75. Peng YF, Shi YH, Ding ZB, Ke AW, Gu CY, Hui B, et al. Autophagy inhibition suppresses pulmonary metastasis of $\mathrm{HCC}$ in mice via impairing anoikis resistance and colonization of HCC cells. Autophagy. 2013;9(12):2056-2068. doi: 10.4161/auto.26398.

76. de Souza ASC, Gonçalves LB, Lepique AP, de Araujo-Souza PS. The role of autophagy in tumor immunology-complex mechanisms that may be explored therapeutically. Front Oncol. 2020;10:603661. doi: $10.3389 /$ fonc. 2020.603661 
77. Kim R, Emi M, Tanabe K. Cancer immunoediting from immune surveillance to immune escape. Immunology. 2007;121(1):1-14. doi: 10.1111/j.1365-2567.2007.02587.x

78. Jiang GM, Tan Y, Wang H, Peng L, Chen HT, Meng XJ, et al The relationship between autophagy and the immune system and its applications for tumor immunotherapy. Mol Cancer. 2019;18(1):17. doi: 10.1186/s12943-019-0944-z.

79. Xia H, Green DR, Zou W. Autophagy in tumor immunity and therapy. Nat Rev Cancer. 2021;21(5):281-297. doi: 10.1038/s41568-021-003442.

80. Katheder NS, Rusten TE. Microenvironment and tumors-a nurturing relationship. Autophagy. 2017;13(7):1241-1243. doi 10.1080/15548627.2017.1310361.

81. Ghislat G, Lawrence T. Autophagy in dendritic cells. Cell Mol Immunol. 2018;15(11):944-952. doi: 10.1038/cmi.2018.2.

82. Tao S, Drexler I. Targeting autophagy in innate immune cells: angel or demon during infection and vaccination? Front Immunol. 2020;11:460. doi: 10.3389/fimmu.2020.00460.

83. Wang Y, Lin YX, Wang J, Qiao SL, Liu YY, Dong WQ, et al. In Situ Manipulation of dendritic cells by an autophagy-regulative nanoactivator enables effective cancer immunotherapy. ACS Nano. 2019;13(7):7568-7577. doi: 10.1021/acsnano.9b00143.

84. Ireland JM, Unanue ER. Autophagy in antigen-presenting cells results in presentation of citrullinated peptides to CD4 T cells. J Exp Med. 2011;208(13):2625-2632. doi: 10.1084/jem.20110640.

85. Yamamoto K, Venida A, Yano J, Biancur DE, Kakiuchi M, Gupta S, et al. Autophagy promotes immune evasion of pancreatic cancer by degrading MHC-I. Nature. 2020;581(7806):100-105. doi: 10.1038/s41586-020-2229-5.

86. Tu SP, Quante M, Bhagat G, Takaishi S, Cui G, Yang XD, et al. IFN- $\gamma$ inhibits gastric carcinogenesis by inducing epithelial cell autophagy and T-cell apoptosis. Cancer Res. 2011;71(12):4247-4259. doi: 10.1158/0008-5472.CAN-10-4009.

87. Li W, Tanikawa T, Kryczek I, Xia H, Li G, Wu K, et al. Aerobic glycolysis controls myeloid-derived suppressor cells and tumor immunity via a specific CEBPB isoform in triple-negative breast cancer. Cell Metab. 2018;28(1):87-103.e6. doi: 10.1016/j.cmet.2018.04.022.

88. Cunha LD, Yang M, Carter R, Guy C, Harris L, Crawford JC, et al. LC3associated phagocytosis in myeloid cells promotes tumor immune tolerance. Cell. 2018;175(2):429-441.e16. doi: 10.1016/j.cell.2018.08.061.

89. Alissafi T, Hatzioannou A, Mintzas K, Barouni RM, Banos A, Sormendi $\mathrm{S}$, et al. Autophagy orchestrates the regulatory program of tumorassociated myeloid-derived suppressor cells. $J$ Clin Invest. 2018;128(9):3840-3852. doi: 10.1172/JCI120888

90. Rao S, Tortola L, Perlot T, Wirnsberger G, Novatchkova M, Nitsch R, et al. A dual role for autophagy in a murine model of lung cancer. Nat Commun. 2014;5:3056. doi: 10.1038/ncomms4056.

91. Mulcahy Levy JM, Thorburn A. Autophagy in cancer: moving from understanding mechanism to improving therapy responses in patients. Cell Death Differ. 2020;27(3):843-857. doi: 10.1038/s41418-0190474-7.

92. Lim SM, Mohamad Hanif EA, Chin SF. Is targeting autophagy mechanism in cancer a good approach? The possible double-edge sword effect. Cell Biosci. 2021;11(1):56. doi: 10.1186/s13578-02100570-z.

93. Marinković M, Šprung M, Buljubašić M, Novak I. Autophagy modulation in cancer: current knowledge on action and therapy. Oxid Med Cell Longev. 2018;2018:8023821. doi: 10.1155/2018/8023821.

94. Han Y, Zhou S, Wang X, Mao E, Huang L. SNHG14 stimulates cell autophagy to facilitate cisplatin resistance of colorectal cancer by regulating miR-186/ATG14 axis. Biomed Pharmacother. 2020;121:109580. doi: 10.1016/j.biopha.2019.109580.

95. Lin JF, Lin YC, Tsai TF, Chen HE, Chou KY, Hwang TI. Cisplatin induces protective autophagy through activation of BECN1 in human bladder cancer cells. Drug Des Devel Ther. 2017;11:1517-1533. doi: 10.2147/DDDT.S126464

96. Qiu S, Sun L, Zhang Y, Han S. Downregulation of BAG3 attenuates cisplatin resistance by inhibiting autophagy in human epithelial ovarian cancer cells. Oncol Lett. 2019;18(2):1969-1978. doi: 10.3892/ol.2019.10494

97. Xiao X, Wang W, Li Y, Yang D, Li X, Shen C, et al. HSP90AA1mediated autophagy promotes drug resistance in osteosarcoma. J Exp Clin Cancer Res. 2018;37(1):201. doi: 10.1186/s13046-018-0880-6.

98. Li X, Lu Y, Pan T, Fan Z. Roles of autophagy in cetuximab-mediated cancer therapy against EGFR. Autophagy. 2010;6(8):1066-1077. doi: 10.4161/auto.6.8.13366

99. Wolpin BM, Rubinson DA, Wang X, Chan JA, Cleary JM, Enzinger PC, et al. Phase II and pharmacodynamic study of autophagy inhibition using hydroxychloroquine in patients with metastatic pancreatic adenocarcinoma. Oncologist. 2014;19(6):637-638. doi: 10.1634/theoncologist.2014-0086.

100. Goldberg SB, Supko JG, Neal JW, Muzikansky A, Digumarthy S, Fidias $\mathrm{P}$, et al. A phase I study of erlotinib and hydroxychloroquine in advanced non-small-cell lung cancer. $J$ Thorac Oncol. 2012;7(10):1602-1608. doi: 10.1097/JTO.0b013e318262de4a.

101. Rosenfeld MR, Ye X, Supko JG, Desideri S, Grossman SA, Brem S, et al. A phase $\mathrm{I} / \mathrm{II}$ trial of hydroxychloroquine in conjunction with radiation therapy and concurrent and adjuvant temozolomide in patients with newly diagnosed glioblastoma multiforme. Autophagy. 2014;10(8):1359-1368. doi: 10.4161/auto.28984.

102. Rangwala R, Leone R, Chang YC, Fecher LA, Schuchter LM, Kramer A, et al. Phase I trial of hydroxychloroquine with dose-intense temozolomide in patients with advanced solid tumors and melanoma. Autophagy. 2014;10(8):1369-1379. doi: 10.4161/auto.29118.

103. Vogl DT, Stadtmauer EA, Tan KS, Heitjan DF, Davis LE, Pontiggia L, et al. Combined autophagy and proteasome inhibition: a phase 1 trial of hydroxychloroquine and bortezomib in patients with relapsed/refractory myeloma. Autophagy. 2014;10(8):1380-1390. doi: 10.4161/auto.29264

104. Rangwala R, Chang YC, Hu J, Algazy KM, Evans TL, Fecher LA, et al. Combined MTOR and autophagy inhibition: phase I trial of hydroxychloroquine and temsirolimus in patients with advanced solid tumors and melanoma. Autophagy. 2014;10(8):1391-1402. doi: 10.4161/auto.29119

105. Mahalingam D, Mita M, Sarantopoulos J, Wood L, Amaravadi RK, Davis LE, et al. Combined autophagy and HDAC inhibition: a phase I safety, tolerability, pharmacokinetic, and pharmacodynamic analysis of hydroxychloroquine in combination with the HDAC inhibitor vorinostat in patients with advanced solid tumors. Autophagy. 2014;10(8):1403-1414. doi: 10.4161/auto.29231.

106. Chi MS, Lee CY, Huang SC, Yang KL, Ko HL, Chen YK, et al. Double autophagy modulators reduce 2-deoxyglucose uptake in sarcoma patients. Oncotarget. 2015;6(30):29808-29817. doi: 10.18632/oncotarget.5060.

107. Boone BA, Bahary N, Zureikat AH, Moser AJ, Normolle DP, Wu WC, et al. Safety and biologic response of pre-operative autophagy inhibition in combination with gemcitabine in patients with pancreatic adenocarcinoma. Ann Surg Oncol. 2015;22(13):4402-4410. doi: $10.1245 / \mathrm{s} 10434-015-4566-4$. 